\title{
The Existence Form, Function and Development Countermeasure of Chinese Wanda Group's Enterprise Sports
}

\author{
Yang Fenghua ${ }^{1 a}$ \\ ${ }^{1}$ Jianghan University of Physical Education, Wuhan 430056 China \\ a382048547@qq.com
}

\begin{abstract}
Keywords: Enterprise sports; Corporate sports culture; The sports function
\end{abstract}
\begin{abstract}
This paper expounds the Chinese commercial real estate on behalf of the enterprise - the Wanda Group, a form of sports, sports role in enterprise development and facing problems, and puts forward some countermeasures for the development of the sports enterprise.
\end{abstract}

\section{Introduction}

Dalian Wanda group was founded in 1988, forming four core industries of commercial real estate, senior hotel, cultural tourism and chain department store. In recent years, Wanda group has been the top 10 enterprises in the private enterprise, and the total economic volume is expanding rapidly. In 2015 , the company was ranked the top of the total assets of private enterprises with a scale of 73.054 billion yuan. Wanda group is a leading enterprise in the real estate industry. It is developing rapidly, with a large scale and strict system. It has outstanding representation in modern enterprises.

The sports activities of the enterprise are regarded as the main component of the enterprise culture, and the cohesion of the enterprise is enhanced while the amateur life is active. In some developed countries, enterprise sports play an important role in national sports. Enterprise sports are important components of China's sports cause, the mental and physical health of the masses of working people is important guarantee, is to strengthen enterprise management, promote the production and upgrade the important method and organizational form of enterprise culture. Therefore, under the modern enterprise system of Chinese enterprise sports an in-depth analysis and research, is helpful for enterprises to the healthy development of sports, is conducive to better develop the function of sports service for China's economic development.

\section{The existence form of sports in enterprises}

\subsection{Staff Sports Activities}

Employee sports is an important carrier and component of enterprise sports development. Modern enterprises pay more and more attention to the important role of staff sports activities, improve the system of staff sports management, investment organization staff sports activities to promote the construction of enterprise culture, to improve employee work and the production efficiency, thus to improve the competitiveness of enterprises. The statistics of sports activities organized by the enterprise employees of Wanda group are shown in table 1.

According to five global times reports 6 life, east China normal university department of psychology of white-collar workers in Shanghai made a survey of job burnout, investigation, a special group of the financial industry, office services industry science and technology, and thus the report revealed that $40 \%$ of respondents felt listless to work ${ }^{[1]}$. In addition, according to the examination results of provincial civil servants in Henan province in 2003 and 2004, the incidence of cervical spondylosis in the civil service was up to $42 \%$ and the incidence of fatty liver was $18 \%$ in 2003. In 2004, sub-health accounted for 51 percent of the total number of participants. Among them, there are only 5 health workers in a unit of 86 , with an abnormal rate of $94.1 \%{ }^{[2]}$. With the rapid development of economy and network, modern office intelligence is becoming more and more stressful. Due to their long time in the fast pace, high efficiency and psychological load, they are not only plagued by various occupational diseases and sub-health, but also have a great impact on their 
physical and mental health. There is an urgent need to strengthen the health of employees in order to adapt to the increasingly stressful work. And office aerobics came into being, and was quickly followed by companies and employees. Wanda group attaches great importance to the physical and mental health of itself and its employees, and the company will arrange the staff of the company with stylistic skills to lead the staff to practice 10-20 minutes of office building exercises every day. Office aerobics is easy to learn, can be very specific to the body to exercise, and to the site, time, space not too big requirements. Office setting-up exercise as a mass fitness programs, office workers in the aerobics exercise, must on the exercise intensity, time and frequency science reasonable arrangement, can play the best exercise effect, achieve the goal of enhanced physique. ${ }^{[3]}$

Table 1. Statistical table of organization of sports activities of enterprise employees of Wanda group

\begin{tabular}{|c|c|c|c|}
\hline Sports events & $\begin{array}{l}\text { Time and } \\
\text { cycle }\end{array}$ & $\begin{array}{c}\text { Proportion of } \\
\text { participants }(\%)\end{array}$ & Group company \\
\hline $\begin{array}{c}\text { New employee quality } \\
\text { development }\end{array}$ & often & 100 & $\begin{array}{c}\text { Group, Headquarters of the company, } \\
\text { subsidiary }\end{array}$ \\
\hline Corporate fun games & Once per year & 100 & Group,Headquarters of the company \\
\hline Enterprise league & 4 times/year & 10 & $\begin{array}{c}\text { Group,Headquarters of the company, } \\
\text { subsidiary }\end{array}$ \\
\hline Individual sports competition & 1 time/quarter & 84 & $\begin{array}{c}\text { Group,Headquarters of the company, } \\
\text { subsidiary }\end{array}$ \\
\hline Office aerobics & 1 time/day & 100 & $\begin{array}{c}\text { Group,Headquarters of the company, } \\
\text { subsidiary }\end{array}$ \\
\hline Enterprise annual meeting & 1 time/day & 100 & $\begin{array}{c}\text { Group,Headquarters of the company, } \\
\text { subsidiary }\end{array}$ \\
\hline
\end{tabular}

\subsection{Corporate Sports Sponsorship}

For many of the post-80s Chinese, the name Wanda is probably the name for football. On March 8, 1994, Wanda group entered the Dalian football club and changed its name to Dalian Wanda football club. In the following years, Dalian Wanda won many top league titles and became the most successful football club in Chinese football. Until 1999, Wanda group was forced out of football because of the referee's troubles. In the past six years, Dalian Wanda has won four titles in the top league of professional football in China and a champion of the Chinese super league. Chinese football professional league history on one of the most successful enterprises of Dalian Wanda group, in the after ten years later, Chinese football back with a new attitude - July 3, 2012, Chinese football "star of hope that Chinese football team went to Europe to study start with Dalian Wanda group and China football association strategic cooperation signing ceremony" was held in Beijing university of technology. Wang jianlin, chairman of Wang jianlin, announced that Wanda group will pay at least rmb500 million in three years to fully support the revitalization of Chinese football. It is understood that this is the largest single sponsorship money in Chinese sports history since the founding of the People's Republic of China. Wanda group's sponsorship of sports is very representative.

Sports sponsorship is refers to the enterprise by sponsoring a sports event or activity, and around the sponsor a series of marketing activities, with the aid of sports activities sponsored by the good social effect, improve the brand awareness and brand image of enterprises, to gain favor and attention by all circles of the society, for enterprises to create a favorable environment to survive and develop. ${ }^{[4]}$ sports sponsorship is beneficial for enterprises to establish a healthy image of the brand, and promote the popularity and reputation of the brand through the halo effect of sports activities. Sports sponsorship is advantageous to the enterprise and the government or social organizations to establish a closer relationship, create a more conducive to enterprise survival of the social environment, which is by the general pure commercial behavior is difficult to achieve. ${ }^{[5]}$ 


\subsection{Enterprise Sports Culture Construction}

The basic elements of modern enterprise sports culture include enterprise concept, target, person, wealth, content and evaluation. Wanda group attaches great importance to the construction of corporate culture, and Wang jianlin puts forward "the spiritual pursuit of the highest level of life pursuit and the management culture of the highest level of enterprise management". Wanda group has established a sound management system and attached great importance to execution, which has provided a strong guarantee for the construction of corporate culture. Wanda group for each new employee orientation, Wanda group learning corporate culture, and through the enterprise system learning and competition, Wanda internal journals, video playback feature films, corporate annual meeting, employee welfare activities, such as a variety of ways to every staff to promote the company's corporate culture. Wanda group has established Asia's largest ski resort in Changbai mountain. At Wanda college, the indoor stadium and outdoor playground were established. Every Wanda plaza project has a fitness club to provide a good fitness environment and facilities for employees and customers. Wanda group is looking for talent in sports and arts, and organizes annual conferences to provide a stage for talents to show their talents and abilities.

\section{The Role Played by Sports in The Development of Wanda Group}

\subsection{The Role of Cultural Construction}

Sports is one of the forms of social culture, and sports has the basic characteristics of cultural products and cultural services. Sports advocated sports ethics of fair, open, comprehensive and harmonious development concept, the idea of harmony between man and nature, everyone is equal, no discrimination, human social equality, unity, friendship, peace, such as thought, is of great significance for the construction of harmonious enterprise culture. ${ }^{[6]}$ the spirit of sports, the content of sports, the function of sports and the means of sports can effectively promote the construction of corporate culture and provide sustained and powerful spiritual impetus for the development of Chinese enterprises.

\subsection{Strengthen Enterprise Cohesion}

With the establishment of the modern enterprise system, employees from "unit person" to "social person", the traditional enterprise small society "fence" was broken, communication between employees and the relationship between human and enterprise diversification, enterprises call for a new kind of values and centripetal force. Sports culture is incomparable to the aggregation and coagulation of human beings, because of sports, the young people who like football sports get together. The Olympic Games bring together people from all over the world for the common ideal of peace, friendship and progress. It can be seen that sport is a kind of social intercourse activity, communication can produce communication. In the sports people through physical contact, mutual cooperation, and encourage each other become human-to-human the resonance of the mind, strengthen the emotional communication between employees, improve the interpersonal relations, enhance the cohesive affinity of the enterprise.

\subsection{Promote Brand Promotion}

Dalian Wanda has played football for six years. Wanda and the football association began in 1993, when Wang jianlin's plan, Dalian Wanda team won the national A league championship four times. It has been said that Wanda could not have become a household name without football.Wang admitted that many people in China know that Wanda started with football. Wanda football championships, 55 unbeaten, coupled with the heat of the football at that time seems to be higher than now, social interest also seems to be higher than now, to the reputation of enterprises laid a good foundation. Brand is the most important for Wang jianlin, the highest level of competition is brand competition. Wanda, which was not able to match the future of the northern war, has laid an excellent investment channel for Wanda's national strategy in the future. 


\subsection{Improve the Physical and Psychological Quality of Employees and Bring Greater Benefits to Enterprises}

Practice shows that the enterprise staff in the intense work, through the sports activities, can make the mind, mental and physical strength, energy to obtain the very good relaxation, and then get pleasure and adjustment, more full of energy to work in the tense. The great intensity and overload in the work, the physical and psychological pressure of the staff is predictable. Sports activities can be released to a great extent caused by working the psychological and mental pressure, through sport and its mood, relaxation too nervous spirit and mental state, alleviate and eliminate long intensive work produced by the body fatigue, quickly recover energy, with a new spirit and strong abundant physical strength into the new work, improve work efficiency.

\section{Wanda Group Enterprise Sports Development Countermeasures}

\subsection{Raise Awareness and Pay Attention to It}

At present, the national fitness ordinance has not be carried out in the enterprise, the rights and interests of workers to participate in sports culture activities, not guaranteed, this is largely restricted the development of sports enterprise. The government and sports departments should attach importance to and actively guide them and increase the support or financing to create a social environment for sports development. Let the national fitness in the enterprise also be able to carry out very well. As companies in sports activities and sports events to the enterprise, at present many sports activities are enterprise management in a heavy task for tight and refuse to cancel some of the activities at random and worker masses happy event, lower the staff sports to the enterprise interest, continue for a long time will affect the development of the sports enterprise. Enterprises should integrate sports into enterprise management, and treat them with a kind of management behavior and performance.

\subsection{Improve the Sports Management System of Enterprises and Guarantee the Development of Sports}

Enterprise sports management system is the behavior standard of enterprise sports, which stipulates the behavior mode and operation mode of enterprise sports, which has obvious mandatory. It should include sports culture development plan, enterprise sports management mode, management organization or organization, development goal, detailed management operation method and reward system. The organization mode, cycle and fund budget of sports activities; The specific methods of corporate sports sponsorship, capital budgeting, supervision and audit methods should be clearly defined and evaluated. The enterprise sports management system must be normative, and only has certain normative ability to play its role. Sports management system can protect enterprise employees to participate in sports activities of time, frequency and funds, its role in enterprise sports sponsorship security, safeguard enterprise rationalization of sports culture construction.

\subsection{Optimize the Enterprise Sports Development Mode}

The development mode of enterprise sports culture mainly includes traditional improvement mode, enterprise and community interaction mode, club mode and integrated mode. : traditional modified model is similar to the past planning model of a vertical management mode, enterprise sports work is not under the instruction in the country, enterprises in such aspects as organization form and the money have greater autonomy, but within the enterprise, is still in the trade union or competent enterprises directly under the leadership of the vertical management mode, forming a vertical flat structure. This model possesses the advantages of well-organized, high efficiency, the disadvantage is that the lack of flexibility attached a lot of manpower and material resources, financial resources, at present, many oversize state-owned enterprise sports using this model. Enterprise and community interaction model: it means that under the unified coordination of the community, enterprises actively invest in human resources, material resources and funds, and implement the dual management and coordination of enterprises and communities. This model is suitable to the social 
development and corporate welfare, possesses the advantages of saving cost, flexible operation, the defect is to organize the implementation of more complex and the consequences of bad coordination will be inefficient. It is suitable for small and medium enterprises, especially enterprise sports in economic development zone. Club mode: this is a kind of industrial action pattern, refers to the sports itself according to the enterprise operation law to carry out work, the enterprise sports market, realize the industrialization development of sports enterprise. Its advantage is to make enterprise sports have the direct production function, the disadvantage is to have certain market risk. at present, many enterprises are making this attempt. Integrated model: in some enterprises, its operation is implemented club mechanism of sports culture, and enterprise cooperation with the community, to form the comprehensive development of sports development mode of enterprise, mainly appear in some large enterprises. In a word, enterprise sports not only needs to be formed, but also needs to be consolidated and improved, so that it can be converted into material strength, spiritual strength and real productive forces.

\subsection{Development Countermeasures of Employees' Sports Activities}

The employee is the main body that participates in the sports activity, has the decisive effect to the development of the worker sports activity. Rich and interesting sports activities promote the promotion of employees' interest in sports activities. The good use of resources is an important foundation for the development of sports activities. The introduction of sports talents plays an important role in the smooth development of enterprise sports activities.Main countermeasures, first of all, innovation workers sports content, and second, is the effective integration of sports resources and provide better fitness conditions for employees, for enterprises to save money, the enterprises should be appropriate to introduce sports talents.

\subsection{Promote the Benign Development of Corporate Sports Sponsorship}

Chinese sports sponsorship started late, and there are many short-term behaviors, too many market development and too many problems. Sponsored enterprises and sports administrative organization, sports organization should actively coordinate, communicate, sponsored by establishing objectives, market system is based on honesty, multi-dimensional evaluation system, the sports humanistic ideas and the sponsor's brand fuses in together, actively and effectively implement and realize the sponsorship cooperation, safeguard the legitimate rights and interests of sponsors, make sports department and the common interests of sponsors get coordination and orderly development, faster to make China's sports sponsorship market towards a healthy development track.

\section{References}

[1] Zhang jian. $40 \%$ white-collar job burnout in Shanghai [N]. Global Times Life, vol.10,pp.11,2005.

[2] Zhang xu. Government departments make compulsory rules for civil servants' physical fitness -- don't get sick in the office [N]. China Sports News, vol.6,pp.2,2005.

[3] Liu xinhua. Research on the theory of office building exercise. China Sports Science and Technology, vol.43,pp.122-127,2007.

[4] Li shixiang,Tang sunna. Research on the status quo and development strategies of sports sponsorship by Chinese enterprises. Hubei Sports Science and Technology, vol.27,pp.136-137,2008.

[5] Chen yibing. Research on how enterprises sponsor sports sponsorship. Journal of Inner Mongolia university of nationalities (natural science edition), vol.24,pp.590-592,2009.

[6] Dong jie, Dong qun. Preliminary discussion on sports culture service [J]. Sports and Science,vol.2,pp. 28-29,2004. 